\title{
Public Perception of Management of Hair Conditions in America: Results from a National Survey
}

\author{
Alexandria Riopelle $^{\mathrm{a}}$ Jacqueline Watchmaker ${ }^{\mathrm{b}} \quad$ Lynne Goldberg $^{\mathrm{b}}$ \\ ${ }^{a}$ Division of Dermatology, Loyola University Chicago Stritch School of Medicine, Maywood, IL, USA; \\ ${ }^{b}$ Department of Dermatology, Boston University School of Medicine, Boston, MA, USA
}

Dear Editor,

Only a few studies have evaluated the general population's perception of the field of dermatology, and all of them have been conducted in Europe [1-3]. They have demonstrated that the average person believes that dermatologists treat skin cancer, inflammatory skin disease, and acne. From the investigators' personal experience, many people in the general public are unaware that dermatologists treat hair and scalp conditions. The objective of this study was to evaluate public awareness that dermatologists treat hair and scalp conditions.

After IRB approval, data were collected from 100 adults via a telephone survey consisting of 5 questions aimed at determining the degree of awareness that dermatologists treat hair and scalp conditions. To obtain a representative sample of the US population, a validated method for random digit dialing was used [4].

A sample of 100 adults from 10 random US area codes completed the telephone survey, with a response rate of $71 \%$. The average age of the responders was 42 years; $54 \%$ were male and $46 \%$ were female. Nearly half of the participants were "unsure" if dermatologists treat hair conditions and $11 \%$ stated that dermatologists do not treat hair conditions (Table 1). Overall, females were more aware
Table 1. Survey study results
Do dermatologists treat hair conditions? $\%(95 \%$ CI)

$\begin{array}{cc}\text { General public } & \\ \text { Yes } & 41.0 \%(32-50) \\ \text { No } & 11.0 \%(5-17) \\ \text { Unsure } & 48.0 \%(39-57) \\ \text { General public: } & \text { males } \\ \text { Yes } & 37.0 \%(28-46) \\ \text { No } & 11.1 \%(5-17) \\ \text { Unsure } & 51.90 \%(42-60) \\ \text { General public: } & \text { females } \\ \text { Yes } & 45.7 \%(36-54) \\ \text { No } & 10.9 \%(5-15) \\ \text { Unsure } & 43.9 \%(34-52)\end{array}$

General public

Yes

No

$11.0 \%(5-17)$

ales

Yes
Do dermatologists treat scalp conditions? $\%(95 \%$ CI $)$

$$
\begin{gathered}
82.0 \%(75-89) \\
0 \\
18.0 \%(11-25) \\
77.8 \%(69-85) \\
0 \\
22.2(14-30) \\
86.4 \%(79-93) \\
0 \\
13.6 \%(6-20)
\end{gathered}
$$

than males that dermatologists treat conditions of the hair. Only $11 \%$ of the participants surveyed stated that they would first seek advice from a dermatologist if they started experiencing hair loss (Fig. 1). Most respondents (82\%) stated that dermatologists treat conditions of the scalp (Table 1).

$\begin{aligned} & \text { karger@karger.com } \\ & \text { www.karger.com/sad }\end{aligned}$
Karger $\%$ 2020 S. Karger AG, Basel


Fig. 1. Where Americans turn to for hair loss advice.

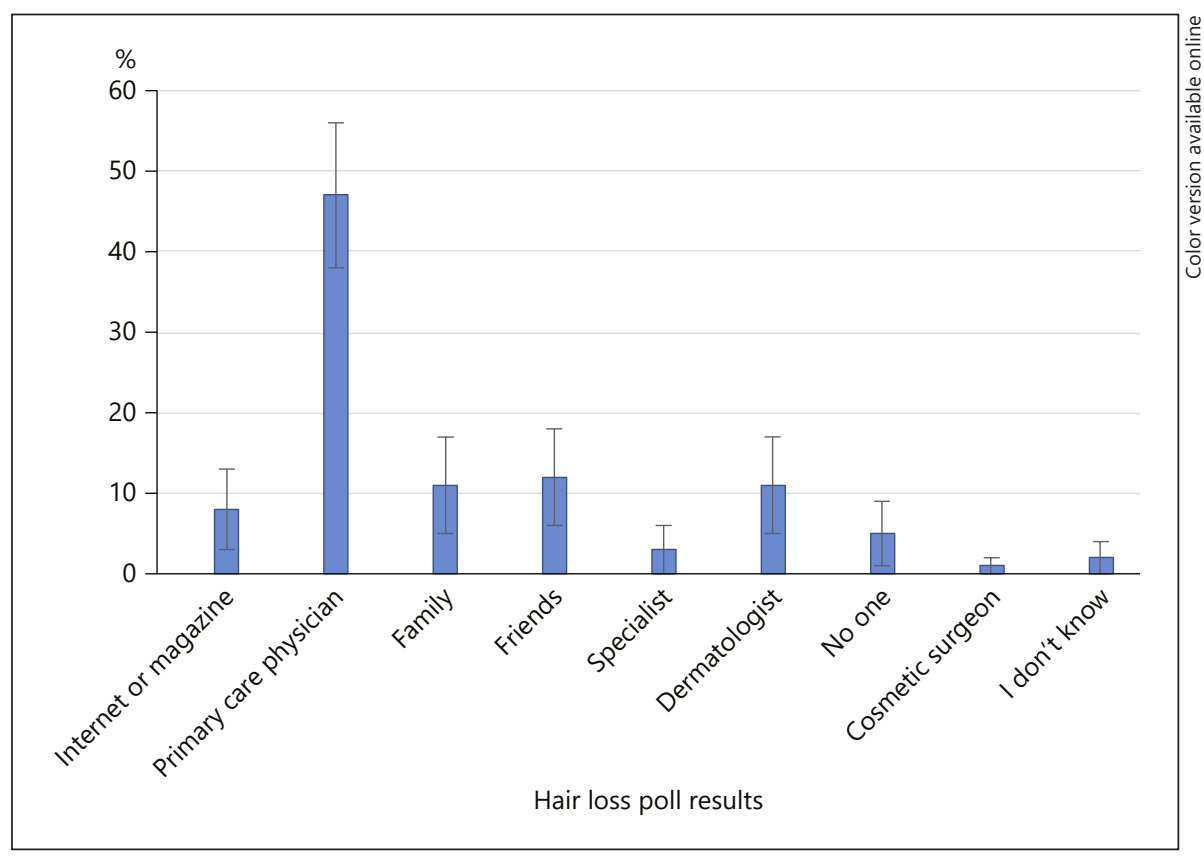

It is estimated that by the age of 50 years, $50 \%$ of men and women will suffer from hair loss, most commonly androgenetic alopecia [5]. Hair loss can be distressing to patients and affect their psychosocial well-being. To our knowledge, this the first study using a nationally representative US sample to assess the public's perception of the treatment of hair and scalp conditions. Our study showed that $95 \%$ of the population would seek advice if they experienced hair loss, reiterating the importance of hair loss in the average person.

The majority (59\%) of participants were either unsure or did not believe that dermatologists treat hair conditions. These data are consistent with those from the European general population. In 2017, a study of 1,015 German citizens reported that $<50 \%$ of the population was aware that dermatologists treat hair loss [3]. This same study found that $12 \%$ were unaware of dermatology as a specialty [3]. Other possible explanations for these findings in the USA include the need to get a referral to seek dermatology care for patients with health maintenance organization (HMO) insurance plans and socioeconomic status. In our data gathered from cities in Illinois, including Harvey and Blue Island, where the average household income is approximately USD 32,500 (USD 28,000 below the national level [6]), none of the respondents reported that they would seek care from a dermatologist. The main limitation of our study was the small sample size; as such, our findings were exploratory and are meant to stimulate discussion on this topic.

Public Perception of the Management of Hair Conditions
There are public campaigns educating patients about skin cancer and sun prevention but none regarding hair loss. Often patients come to a dermatologist at a late stage of disease when there is little that can be done. We surmise that better education of the community will translate into more timely and appropriate treatment of hair conditions. Future directions of study include educating dermatology and primary-care providers as well as the general public on the important role that dermatologists play in managing conditions of the hair.

\section{Disclosure Statement}

The authors have no conflicts of interest to declare.

\section{Funding Sources}

The authors did not receive any funding for this study.

\section{Author Contributions}

Ms. Alexandria Riopelle, Dr. Jacqueline Watchmaker, and Dr. Lynne Goldberg each made substantial contributions to the conception and drafting of the work and final approval of the version to be published. All three agree to be accountable for all aspects of the work. 


\section{References}

1 Gisondi P, De Angelis G, Venturelli G, Girolomoni G. Public perception of dermatology and dermatologists in Italy: results from a population-based national survey. J Eur Acad Dermatol Venereol. 2017 Dec;31(12):211923.

2 Augustin M, Stadler R, Reusch M, Schäfer I, Kornek T, Luger T. Skin cancer screening in Germany - perception by the public. J Dtsch Dermatol Ges. 2012 Jan;10(1):42-9.
3 Augustin M, Eissing L, Elsner P, Strömer K, Schäfer I, Enk A, et al. Perception and image of dermatology in the German general population 2002-2014. J Eur Acad Dermatol Venereol. 2017 Dec;31(12):2124-30.

4 Brezinski EA, Harskamp CT, Ledo L, Armstrong AW. Public perception of dermatologists and comparison with other medical specialties: results from a national survey. J Am Acad Dermatol. 2014 Nov;71(5):875-81.
5 Price VH. Treatment of hair loss. N Engl J Med. 1999 Sep;341(13):964-73.

6 Guzzman G. Census 2017: Household Income: 2017. Report No.: ACSBR/17-01. Washington (DC): US Census Bureau; 2018. pp 1-11. Report No.: ACSBR/17-01. 